\title{
Dopaminergic activity and behaviour in SOCS2 transgenic mice: revealing a potential drug target for schizophrenia
}

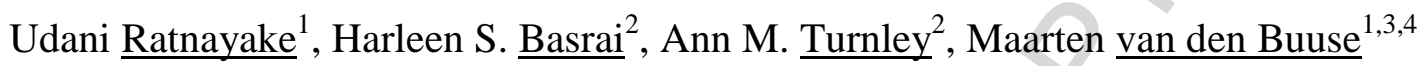

(1) Florey Institute of Neuroscience and Mental Health, University of Melbourne,

\section{Australia}

(2) Department of Anatomy and Neuroscience, University of Melbourne, Australia

(3) Department of Pharmacology and Therapeutics, University of Melbourne, Australia

(4) School of Psychological Science, La Trobe University, Melbourne, Australia.

\section{Correspondence to:}

Prof. Maarten van den Buuse

School of Psychological Science

Faculty of Science, Technology and Engineering

La Trobe University

Bundoora, VIC 3086, Australia

E:m.vandenbuuse@latrobe.edu.au

$\mathrm{Ph}:+61394795257$

Running title: SOCS2, dopamine and schizophrenia 


\begin{abstract}
Alterations in immune function have been implicated in the etiopathogenesis of schizophrenia. Specifically, the induction of inflammatory cytokines, which are important immunological factors in infection or inflammation, may be critical factors altering the normal course of brain development and increasing schizophrenia risk. Suppressor of cytokine signalling 2 (SOCS2) can negatively regulate the signalling of cytokines. The present study aimed to determine the behavioural phenotype of transgenic mice overexpressing SOCS2 (SOCS2 Tg) in paradigms of relevance to schizophrenia. Both male and female SOCS2 Tg mice displayed reduced locomotor hyperactivity after the administration of the dopamine releaser, amphetamine, compared to wildtype controls (WT). However, only male SOCS2 Tg mice showed enhanced prepulse inhibition compared to WT. Dopamine D2 receptors mRNA expression was reduced and dopamine transporter mRNA expression was increased in the nucleus accumbens of female, but not male, SOCS2 Tg mice, compared to WT. The role of hyperdopaminergia has long been implicated in the etiology of schizophrenia. This study shows that over-expression of SOCS2 reduces the psychostimulant effects of amphetamine, enhances PPI, and alters mesolimbic dopaminergic activity. SOCS2 may provide a novel target in the development of treatments for schizophrenia.
\end{abstract}

Keywords: SOCS2, schizophrenia, dopamine, nucleus accumbens, locomotor hyperactivity, prepulse inhibition 


\section{INTRODUCTION}

Schizophrenia is a neurodevelopmental disorder, thought to originate from aberrations in brain development during early fetal and postnatal stages. There is increasing evidence for the role of the immune system in the etiopathogenesis of schizophrenia (Miller et al., 2011, Nawa and Takei, 2006, Patterson, 2009, Potvin et al., 2008). Of particular interest is the abnormal expression of inflammatory cytokines, a common response by the immune system to varying infections. For example, epidemiological studies, that found an increased incidence of schizophrenia in individuals exposed to a bacterial or viral infection during prenatal life, indicate that a critical factor altering normal brain development is an induction of inflammatory cytokines (Brown et al., 2004, Buka et al., 2001). In addition, abnormalities in the constitutive expression of inflammatory cytokines, such as interleukin (IL)-6, IL-8 and IL-10, have been found in the serum of schizophrenic patients (Maes et al., 2002, Potvin et al., 2008).

The Janus kinases (JAK) and signal transducers and activators of transcription (STAT) signalling pathway has an important role in driving biological responses to cytokines (Rawlings et al., 2004). Factors that regulate the JAK-STAT pathway, and thus mediate cytokine signalling, may also provide a novel target for treatment of schizophrenia. The primary function of a family of eight proteins, called suppressor of cytokine signalling (SOCS), is to negatively regulate the JAK-STAT pathway via a negative feedback loop, and therefore suppress the signalling of cytokines (Piessevaux et al., 2008).

Of the eight SOCS family proteins, SOCS2 is one of the more extensively studied. SOCS2 is well characterised as an inhibitor of growth hormone signalling, however, it has now also been found to regulate signalling of various other growth factors and cytokines (Goldshmit et 
al., 2004a, Goldshmit et al., 2004b, Greenhalgh et al., 2002, Jegalian and Wu, 2002, Metcalf et al., 2000, Rico-Bautista et al., 2006, Uren and Turnley, 2014, Wang et al., 2004). We have previously found that transgenic mice that overexpress SOCS2 (SOCS2 Tg) display an enhanced survival of newly-born adult hippocampal neurons. Additionally, these mice show enhanced exploratory activity and less anxiety in novel environments (Ransome and Turnley, 2008). In contrast, animal models of schizophrenia have previously reported deficits in exploratory activity and heighted anxiety behaviours (Karl et al., 2007, Meyer et al., 2005, Meyer et al., 2006). In our previous study, in which only male SOCS2 $\mathrm{Tg}$ mice were assessed, we also found a near-significant increase in prepulse inhibition (PPI) (Ransome and Turnley, 2008). PPI is a commonly used test, in humans and rodents, to assess sensory gating. Deficits in this neurological process are commonly reported in human studies and animal models of schizophrenia (Braff et al., 1992, Grillon et al., 1992, Perry et al., 1999, van den Buuse et al., 2003). The dopaminergic system plays a major role in the modulation of sensory gating, for example administration of dopamine (DA) receptor-2 (DR2) agonists disrupts prepulse inhibition (Mansbach et al., 1988, Peng et al., 1990, Swerdlow et al., 1990). Abnormalities in the GABAergic neurotransmitter system, which also plays a role in gating of sensory information, have also been implicated in schizophrenia, including changes in subclasses of GABAergic interneurons. Our group has previously found an increase in cell densities of calretinin and calbindin subclasses of interneurons, as well as an increase in synaptic density and dendritic branching, in the cortex of SOCS2 Tg mice (Ransome and Turnley, 2005).

Currently the main treatment method for schizophrenia is antipsychotic agents that primarily target the DA system; these drugs are often associated with several problems including intolerable side effects and treatment-resistance in a significant proportion of patients. 
Therefore, there is an urgent need to identify novel targets for new treatment strategies. As SOCS2 Tg mice appear to display an opposing behavioural phenotype compared to the endophenotypes found in animal models of schizophrenia, it is possible that SOCS2 may provide a unique target in the development of new treatments for schizophrenia.

Therefore in the present study, we aimed to further assess the behaviour of male and female SOCS2 Tg mice in behavioural paradigms of schizophrenia and identify changes in the dopaminergic system. We used amphetamine-induced locomotor hyperactivity as a model of psychosis, with an increase in dopamine release by amphetamine administration mimicking hyperdopaminergia (van den Buuse, 2010). Prepulse inhibition of acoustic startle (PPI) was then measured to assess sensory gating, which is reduced in schizophrenia. Several previous studies have shown that both amphetamine-induced locomotor hyperactivity and disrupted prepulse inhibition are reversed by antipsychotic treatment (Geyer et al., 2001, Geyer and Moghaddam, 2002, van den Buuse, 2010, van den Buuse et al., 2005). Finally, expression of the DR2 and dopamine transporter (DAT) were assessed in the frontal cortex and nucleus accumbens. 


\section{EXPERIMENTAL PROCEDURES}

\section{$\underline{2.1 \text { Animals }}$}

Wildtype (WT) C57B1/6 and SOCS2 transgenic (Tg) mice on the C57B1/6 genetic background were obtained from a breeding colony at the University of Melbourne. Mice were housed in individually-ventilated cages with food and water ad libitum and kept on a constant 12h light/dark cycle. All male and female animals behaviourally tested were between 12 and 16 weeks of age with all procedures performed during the light phase. All experimental procedures were approved by the Animal Experimentation Ethics Committee of the Florey Neuroscience Institutes, University of Melbourne, Australia.

\subsection{Locomotor Hyperactivity}

Analysis of spontaneous and hyperlocomotor activity was measured with eight clear plastic photocell boxes (MedAssociates, USA) of $27.3 \mathrm{~cm} \times 27.3 \mathrm{~cm} \times 20.3 \mathrm{~cm}(\mathrm{~L} \mathrm{x} \mathrm{W} \mathrm{x} \mathrm{H}$ ), with 16 x 16 x 16 arrays of photobeams surrounding the perimeter to track animal movement. Mice were individually placed in the boxes to measure baseline locomotor activity for an hour, after which the animals were injected intraperitoneally and hyperlocomotor activity was assessed for a further two hours. Treatments were saline, $1 \mathrm{mg} / \mathrm{kg}$ and $3 \mathrm{mg} / \mathrm{kg}$ amphetamine $(\mathrm{AMPH})$ in saline. Drugs were tested in each of the mice in a pseudo-randomized schedule with a 3-4 day break between each session.

\section{$\underline{2.3 \text { Prepulse Inhibition (PPI) }}$}

A week after the conclusion of locomotor testing, PPI was measured with ten automated startle chambers (SR-LAB, San Diego Instruments, San Diego, CA, USA). Mice were placed in a Plexiglas cylinder (3.8 $\mathrm{cm}$ diameter) which was secured to a platform with a piezoelectric 
accelerometer mounted under it to detect whole-body startle response. A single PPI session included 104 trials and lasted for approximately $40 \mathrm{~min}$. There was an initial $3 \mathrm{~min}$ acclimation period with continuous background white noise only, which continued throughout the rest of the session. The first and last eight trials were presented at $115 \mathrm{~dB}$. The 88 trials in-between were presented in a random order of sixteen $115 \mathrm{~dB}$ startle pulses, and 72 prepulse-pulse trials including eight of each prepulse (PP) intensity of 2, 4, 8, $16 \mathrm{~dB}$ over background and eight "no-stimulus" trials, where no pulse was presented. Each startle pulse was $40 \mathrm{~ms}$ in duration, the prepulse was $20 \mathrm{~ms}$ and there was either a $30 \mathrm{~ms}$ or $100 \mathrm{~ms}$ interstimulus interval (ISI) between the prepulse and the pulse. Only PPI measured from 100ms ISI is presented as this ISI provided more reliable results. Percentage PPI was calculated with the formula: $100 \times[($ pulse-alone trials - prepulse-trials)/pulse-alone trials].

\subsection{Dissection of the brain}

Following behavioural analysis, mice were culled by cervical dislocation at 22-24 weeks of age. Brains were removed immediately after decapitation, frozen on dry-ice and stored at $-80^{\circ} \mathrm{C}$. In order to collect the nucleus accumbens (NAc) and medial prefrontal cortex (mPFC), two $2.0 \mathrm{~mm}$ thick coronal slices were obtained at approximately bregma $4.70-2.70$ for coronal section 1, and bregma 2.70-0.70 for coronal section 2 (see Figure 1). Slices were submerged in RNAlater (Life Technologies, USA) and using a scalpel and fine curved forceps the regions of interest were dissected. The dissected region of the mPFC contained the prelimbic (PrL), infralimbic (IL), cingulate (Cg1) and secondary motor cortex (M2). The dissected region of NAc contained the accumbens shell (AcbSh), the lateral accumbens shell (LAcbSh) and the accumbens core (AcbC) (Paxinos, 2005). 


\subsection{Ribonucleic acid (RNA) extraction and quantitative real-time PCR (qRT-PCR)}

RNA was purified from each region using RNeasy Mini Kit (QIAGEN, Valencia, CA) and DNase treated using a DNase free kit (QIAGEN). For the nucleus accumbens and medical prefrontal cortex, $0.5 \mu \mathrm{g}$ and $1 \mu \mathrm{g}$ of total RNA was reverse transcribed respectively, using TaqMan Reverse Transcription kit (Applied Biosystems, USA). Expression of target genes was determined by qRT-PCR using gene specific primers and SYBR Green mastermix (Applied Biosystems), on the ViiA 7 real-time PCR cycler (Applied Biosystems). Primers used for dopamine receptor 2 (Drd2), Slc6a3 or dopamine transporter (DAT) and 18s are listed in Table 1. qRT-PCR cycling conditions for all genes consisted of an initial denaturation step of $95^{\circ} \mathrm{C}$ for $10 \mathrm{~min}$, followed by 40 cycles consisting of $95^{\circ} \mathrm{C}$ for $15 \mathrm{sec}$ and $60^{\circ} \mathrm{C}$ for $1 \mathrm{~min}$. A dissociation curve was also performed at the end of each run. Samples were run in triplicate for the genes of interest and the housekeeping gene, $18 \mathrm{~s}$.

Briefly, the relative expression within the sample $\left(\Delta \mathrm{C}_{\mathrm{T}}\right)$ was measured from the qPCR data by subtracting the mean cycle threshold $\left(\mathrm{C}_{\mathrm{T}}\right)$ for the housekeeping gene $(18 S)$ from the mean $\mathrm{C}_{\mathrm{T}}$ value for the gene of interest. This number was then inserted into the formula $2^{-\Delta \mathrm{CT}}$ to give a final arbitrary expression value. This expression value $\left(2^{-\Delta \mathrm{CT}}\right)$ for each group was divided by the mean $2^{-\Delta \mathrm{CT}}$ of the male WT treatment group to give a final value of expression, relative to the mean value of that obtained for the male WT group, for the gene of interest.

\subsection{Data analysis and statistics}

Body weight and locomotor hyperactivity data were analysed using a 2-way repeated measured analysis of variance (time $\mathrm{x}$ gene $\mathrm{x}$ sex). Prepulse inhibition and gene expression data were analysed using a 2-way analysis of variance (gene x sex). Results are expressed as mean \pm S.E.M. and were considered statistically significant at the $\mathrm{P}<0.05$. 


\section{RESULTS}

\section{$\underline{3.1 \text { Body Weight }}$}

The average body weight of SOCS2 Tg mice of both sexes was greater than that of their WT littermates (Figure 2, main effect of Genotype $F_{(1,24)}=22.8, p<0.0001$ ). As expected, WT and SOCS2 females had significantly lower body weights than their male littermates (main effect of $\left.\operatorname{Sex} F_{(1,24)}=186.9, p<0.0001\right)$.

\subsection{Amphetamine-induced locomotor hyperactivity}

There were significant no differences in locomotor activity between sexes or genotypes in the pre-injection habituation period (Figure 3). Treatment with $1 \mathrm{mg} / \mathrm{kg}$ amphetamine (1AMPH) increased locomotor activity (Figure $3 \mathrm{~A}$ and $\mathrm{B}$, main effect of Drug $F_{(1,25)}=33.5, p<0.001$ ), with this effect tending to be greater in WT controls than SOCS2 mice Tg in females, but not males (Figure 3A and B, Drug x Sex x Genotype interaction $F_{(1,25)}=4.09, p=0.054$ ). The effect of $1 \mathrm{mg} / \mathrm{kg}$ of amphetamine peaked at around $15 \mathrm{~min}$ after injection in (Drug $\mathrm{x}$ Time interaction $\left.F_{(23,575)}=5.65, p=<0.001\right)$, with this effect significantly greater in WT controls than SOCS2 mice Tg in females, but not males (Figure 3B, Drug x Time x Sex x Genotype interaction $\left.F_{(23,575)}=1.92, p=0.006\right)$.

Treatment with $3 \mathrm{mg} / \mathrm{kg}$ of amphetamine induced marked hyperactivity (Figure 3C and D, main effect of Drug, $\left.F_{(1,25)}=151.93, p<0.001\right)$, which was not different between female and male mice. This effect was greater in WT controls than in SOCS Tg mice (Figure 3C and D, Drug x Genotype interaction $\left.F_{(1,25)}=6.17, p=0.02\right)$. The effect of treatment with $3 \mathrm{mg} / \mathrm{kg}$ of amphetamine peaked at around 30min after injection in (Figure 3C and D, Drug $\mathrm{x}$ Time interaction $\left.F_{(23,575)}=47.93, p<0.001\right)$, with this effect being significantly greater in WT controls than in SOCS Tg mice (Drug x Time x Genotype interaction $F_{(23,575)}=3.71, p<0.001$ ). 
This genotype difference in locomotor distance moved after treatment with $3 \mathrm{mg} / \mathrm{kg}$ of amphetamine was similar in male and female mice.

\section{$\underline{3.3 \text { Startle and prepulse inhibition of startle }}$}

There was significant startle habituation over the course of the experiment (main effect of Block $\left.F_{(3,72)}=7.45, p<0.001\right)$, but there were no differences between the sexes or genotypes in average startle response (Figure 4A) or startle habituation (data not shown). Average \%PPI was higher in SOCS2 Tg mice than in WT controls in males, but not females (Figure 4B, Sex x Genotype interaction, $\left.F_{(1,25)}=5.48, p=0.027\right)$. As expected, there was a significant increase in PPI with prepulse intensity (Figure 4C and D, main effect of Intensity $F_{(3,75)}=7.45$, $p<0.001)$ but there was no interaction of prepulse intensity with genotype or sex.

\subsection{Dopamine 2 receptor 2 (D2R) and dopamine transporter (DAT) gene expression}

A significant Sex $x$ Genotype interaction was found in mRNA expression of D2R in the NAc $(\mathrm{F}(1,16)=4.52, p=0.049$; Figure $5 \mathrm{~A})$, with female, but not male SOCS2 Tg mice showing reduced expression. Female SOCS2 Tg mice also showed a highly significant increase in DAT mRNA expression in the NAc compared to wildtypes (Sex x Genotype interaction, $\mathrm{F}(1,16)=15.52, p=0.001$; Figure $5 \mathrm{~B})$, which, again, was not found in males. In addition, an overall sex difference was found in mRNA expression of DAT in the NAc $(F(1,16)=35.70$, $p<0.0001$; Figure 5B), with female mice showing higher expression compared to male littermates. There was no main effect of sex or genotype on D2R or DAT expression in the medial prefrontal cortex (Figure 5). 


\section{DISCUSSION}

Animal models, including genetically-modified mice and rats, are widely used in schizophrenia research, and are particularly useful to study symptomology and the associated mechanisms. In the present study, it was found that SOCS2 transgenic mice display altered amphetamine-induced locomotor hyperactivity, PPI, and dopaminergic activity in the nucleus accumbens. However, these phenotypes were highly sex-dependent with only male SOCS2 Tg mice showing enhanced PPI, whereas only female SOCS2 Tg mice were found to have alterations in DAT and DR2 mRNA expression levels. Current antipsychotics are effective at treating psychotic and positive symptoms of schizophrenia, however these drugs can also be associated with treatment resistance and severe side effects. SOCS2 may provide a unique novel target for developing adjunctive treatments for schizophrenia.

Dopaminergic dysfunction has been implicated in the neuropathology of schizophrenia for over 40 years. The dopamine hypothesis of schizophrenia suggests that dopaminergic hyperactivity plays a role in the aetiology of the positive symptoms of the disease. This theory was based on pharmacologic evidence that nearly all effective antipsychotic drugs are dopamine receptor antagonists (Meltzer and Stahl, 1976). Post-mortem and in-vivo neuroimaging studies, showing an increase in striatal D2R density in schizophrenic patients (Crawley et al., 1986, Laruelle, 2000, Mita et al., 1986, Owen et al., 1978, Zakzanis and Hansen, 1998), were furthermore essential in establishing the initial dopamine hypothesis of schizophrenia (Howes and Kapur, 2009). The dopamine hypothesis was further strengthened by evidence that administration of dopamine receptor agonists or releasers, such amphetamine, is able to induce psychotic episodes in healthy subjects, similar to those seen in schizophrenic patients (Ellinwood et al., 1973, Snyder, 1973). Although psychotic episodes, which can be categorised into the positive symptom cluster, are uniquely human, animal 
models of schizophrenia have attempted to measure these symptoms with locomotor hyperactivity and PPI (van den Buuse, 2010).

Numerous animal studies have shown that treatment with the psychostimulant, amphetamine, causes locomotor hyperactivity, which can be seen as having construct validity to model hyperdopaminergia in humans (van den Buuse, 2010). New antipsychotics are often screened to determine if they are effective at preventing the effects of psychostimulant drugs (Leite et al., 2008). Clinically used classic and atypical antipsychotics, such as haloperidol, clozapine and sulpiride, have been shown to reduce amphetamine-induced locomotor hyperactivity (van den Buuse, 2010). The present study reveals that SOCS2 $\mathrm{Tg}$ mice also display reduced locomotor hyperactivity when treated with amphetamine, compared to WT controls. These results suggest an over-expression of SOCS2 has antipsychotics-like effects, possible due to its actions via the dopaminergic system.

The locomotor-activating effects of low doses of amphetamine, such as the dose chosen for this study $(3 \mathrm{mg} / \mathrm{kg})$, are thought to be mediated by the mesolimbic DA system (Geyer and Moghaddam, 2002, van den Buuse, 2010). Therefore changes in the mesolimbic, as well as the mescocortical, DA system in SOCS2 Tg mice were investigated in this study. These pathways are also known to play a crucial role in cognitive, emotional and reward-related behaviours, as well as executive function; behaviours that are altered in schizophrenia. The mesolimbic dopamine pathway, where dopamine cell bodies in the ventral tegmental area (VTA) project into the forebrain, including in the NAc, plays a role in motivation and reward seeking behaviour. Female SOCS2 Tg mice showed reduced D2R expression in the NAc and increased expression of DAT, the main presynaptic reuptake mechanism into DA terminals in this region. The mesocortical dopamine system, where neurons that project from the VTA 
into cortrical cerebellar areas such as the prefrontal cortex (PFC), is involved in cognitive and executive functions (Brunelin et al., 2013). There were no differences between SOCS2 Tg and WT mice in mRNA expression of D2R or DAT in the medial aspect of the PFC.

PPI, a measure of sensorimotor gating, is deficient in schizophrenia patients and therefore a commonly measured factor in animal models of the disease (van den Buuse, 2010). The administration of direct dopamine receptor agonists, such as apomorphine, and the dopamine releaser, amphetamine, has been consistently shown to disrupt PPI (reviewed in Geyer et al., 2001). In contrast, antipsychotics, that have dopamine antagonistic effects, have been previously shown to increase PPI in humans (Csomor et al., 2008, Vollenweider et al., 2006) and in animal models of disrupted PPI (Bakshi and Geyer, 1995, Bakshi et al., 1994). Therefore the enhancement of PPI in male SOCS2 Tg mice compared to WT controls, in combination with a decrease in amphetamine-induced locomotor activity, found in this study, suggests a reduction in dopaminergic activity. In female SOCS2 Tg mice, the decrease in $\mathrm{D} 2 \mathrm{R}$, particularly if presynaptic, and an increase in DAT mRNA expression in NAc, may have resulted in a compensatory increase in DA synthesis (Howes and Kapur, 2009), preventing the hypo-dopaminergic-related increase in PPI seen in males. The altered expression of DR2 and DAT in female SOCS2 Tg mice is reminiscent of similar changes in these parameters in estrogen-treated rats (Chavez et al., 2010) suggesting a role of elevated estrogen levels mediating these female-specific effects of SOCS2 over-expression. However, further studies are needed to directly measure dopaminergic activity in SOCS2 Tg mice, for example by micro-dialysis.

The mechanisms by which increased SOCS2 expression may exert anti-psychotic effects, remain to be determined. Previous studies have shown that mice over-expressing SOCS2 
showed increased density of calretinin- and calbindin-positive, but not paravalbumin or somatostatin-positive cells, in the prefrontal cortex (Ransome and Turnley, 2005). Reduced density of GABAergic interneurons has been shown in post-mortem brains of patients with schizophrenia (Lewis et al., 2012), however the changes were largely localized to parvalbumin- and somatostatin-positive cells (Lewis et al., 2012, Morris et al., 2008). Therefore the effect of SOCS2 on interneuron density is unlikely to explain its potential antipsychotic-like effect. Moreover, interneuron density in the striatum was not altered in SOCS2 over-expressing mice (Ransome and Turnley, 2005).

An alternative explanation for the present results could be a reduced effect of inflammatory cytokines on dopaminergic activity in the brain. Several studies have shown schizophrenialike behavioural abnormalities and mesolimbic and mescocortical DA system dysfunction caused by prenatal exposure to infection. For example, such mice show enhanced amphetamine-induced locomotor hyperactivity and disruptions of PPI (Eyles et al., 2012, Feleder et al., 2010, Meyer and Feldon, 2009, Ozawa et al., 2006), the opposite of what is seen in the present study. Given the role of the SOCS proteins in regulating the JAK-STAT pathway and thereby biological responses to cytokines, it is possible that SOCS2 transgenic mice represent the opposite of this schizophrenia-like phenotype in animal models of developmental immune-stimulation. As an extension, it could be predicted that the effects prenatal exposure to immune stimulation would be prevented in SOCS2 Tg mice. Given the role of SOCS in regulating cytokine and dopaminergic signalling, indirectly this study also supports the use of anti-inflammatory agents, such as aspirin, as therapeutics for schizophrenia. Aspirin, a popular non-steroidal anti-inflammatory drug, has been previously shown to be effective at reducing symptoms of schizophrenia when given as adjunctive treatment with antipsychotic drugs (Laan et al., 2010). Aspirin is known to trigger the 
generation of anti-inflammatory lipid mediators, lipoxins. The immune-regulatory functions of lipoxins are dependent on the induction and activity of SOCS2 (Machado et al., 2006).

SOCS2 over-expression has been shown to induce a number of other effects in the brain which could potentially be involved in the altered behavioural and neurochemical phenotype observed in the transgenic mice in the present study. For example, SOCS2 over-expression increased expression of the Tropomyosin-related kinase A (TrkA) neurotrophin receptor (Uren and Turnley, 2014). Levels of the neurotrophin, brain-derived neurotrophin (BDNF), have been shown in post-mortem studies to be significantly reduced in schizophrenia (Green et al., 2011, Weickert et al., 2003). However, the ligand for most of the effects of BDNF in the adult brain is TrkB rather than TrkA (Uren and Turnley, 2014) so the relevance of the change in TrkA levels for the antipsychotic-like phenotype in SOCS transgenic mice remains to be clarified. The role of other effects of SOCS2 over-expression, such as enhanced neurogenesis and altered growth hormone responses, in the present results remains to be determined.

\section{CONCLUSION}

The present study has found evidence to suggest a role for SOCS2 in mediating dopaminergic signalling, including presynaptic DA function. The role of dopamine in the etiology of schizophrenia still continues to be the enduring hypothesis of the disease (Di Forti et al., 2007, Eyles et al., 2012, Howes and Kapur, 2009). It has been suggested that future drug development and research should focus on mediating presynaptic dopaminergic factors, as current treatments for schizophrenia, which mostly mediate postsynaptic dopaminergic function, are often associated with treatment resistance and intolerable side effects. 
Therefore, SOCS2 may provide a unique target in the development of novel treatments for schizophrenia. 


\section{ACKNOWLEDGEMENTS}

This work was supported by the National Health and Medical Research Council of Australia (NHMRC). Additional support was obtained by way of operational infrastructure funding from the Victorian State Government. These funding sources had no role in the study's design, the collection, analysis and interpretation of the data, the writing of the report, or the decision to submit the article for publication. 


\section{FIGURE LEGENDS}

Figure 1. Representative diagram of the two coronal sections of $2 \mathrm{~mm}$ taken from the forebrain at approximately bregma 4.70-2.70 (Slice 1, A) and 2.70-0.70 (Slice 2, B) for the dissection of the mPFC and NAc, respectively. Adapted from Paxinos (2005).

Figure 2. Body weight in male and female wild-type and SOCS2 Tg mice. Data are expressed as mean \pm SEM. $* * p<0.001$ compared to wild-type.

Figure 3. The effects of $1 \mathrm{mg} / \mathrm{kg}(\mathrm{A}, \mathrm{B})$ and $3 \mathrm{mg} / \mathrm{kg}(\mathrm{C}, \mathrm{D})$ amphetamine treatment on locomotor activity in male $(\mathrm{A}, \mathrm{C})$ and female $(\mathrm{B}, \mathrm{D})$ wild-type and SOCS2 Tg mice. Data are expressed as mean \pm SEM. $* p<0.05$ Drug x Genotype effect.

Figure 4. Average startle (A) and average \%PPI (B) in wild-type and SOCS2 Tg mice. Panels $\mathrm{C}$ and D depict \%PPI for each prepulse intensity for male and female mice, respectively. Data are expressed as mean \pm SEM. ${ }^{*} p<0.05$ compared to wild-type males.

Figure 5. Relative dopamine D2 receptor and dopamine transporter (DAT) expression in the nucleus accumbens and medial prefrontal cortex in wild-type and SOCS2 Tg mice. Data are expressed as mean \pm SEM. ${ }^{*} p<0.05, * * p<0.01$ compared to wild-type females. 


\section{TABLE 1}

Primer sequences for Drd2, Slc6a3 (DAT) and 18S (housekeeping) gene

Gene

Drd2 (encoding gene for

dopamine D2 receptor)

Slc6a3 (encoding gene for dopamine transporter) $18 \mathrm{~S}$

\section{Primer}

forward 5'- CCATGCCCAATGGCAAA 3'

reverse 5'- GAGCTTCCTGCGGCTCATC -3'

forward 5'-TCATCAATGCCACGACTCTG -3'

reverse 5'-AACTCTAGCGATGGCCTGG -3'

forward 5'- GGCCCAACGAAGAAAACCAT -3'

reverse 5'-AGCATCACCCGGGAAGTG -3' 


\section{References}

Bakshi VP, Geyer MA. Antagonism of phencyclidine-induced deficits in prepulse inhibition by the putative atypical antipsychotic olanzapine. Psychopharmacology (Berl) 1995;122:198201.

Bakshi VP, Swerdlow NR, Geyer MA. Clozapine antagonizes phencyclidine-induced deficits in sensorimotor gating of the startle response. J. Pharmacol. Exp. Ther. 1994;271:787-94.

Braff DL, Grillon C, Geyer MA. Gating and habituation of the startle reflex in schizophrenic patients. Arch. Gen. Psychiatry 1992;49:206-15.

Brown AS, Begg MD, Gravenstein S, Schaefer CA, Wyatt RJ, Bresnahan M, et al. Serologic evidence of prenatal influenza in the etiology of schizophrenia. Arch. Gen. Psychiatry 2004;61:774-80.

Brunelin J, Fecteau S, Suaud-Chagny MF. Abnormal striatal dopamine transmission in schizophrenia. Curr. Med. Chem. 2013;20:397-404.

Buka SL, Tsuang MT, Torrey EF, Klebanoff MA, Wagner RL, Yolken RH. Maternal cytokine levels during pregnancy and adult psychosis. Brain Behav. Immun. 2001;15:411-20.

Chavez C, Hollaus M, Scarr E, Pavey G, Gogos A, van den Buuse M. The effect of estrogen on dopamine and serotonin receptor and transporter levels in the brain: an autoradiography study. Brain Res. 2010;1321:51-9.

Crawley JC, Owens DG, Crow TJ, Poulter M, Johnstone EC, Smith T, et al. Dopamine D2 receptors in schizophrenia studied in vivo. Lancet 1986;2:224-5.

Csomor PA, Stadler RR, Feldon J, Yee BK, Geyer MA, Vollenweider FX. Haloperidol differentially modulates prepulse inhibition and p50 suppression in healthy humans stratified for low and high gating levels. Neuropsychopharmacology 2008;33:497-512.

Di Forti M, Lappin JM, Murray RM. Risk factors for schizophrenia--all roads lead to dopamine. Eur. Neuropsychopharmacol. 2007;17 Suppl 2:S101-7.

Ellinwood EH, Jr., Sudilovsky A, Nelson LM. Evolving behavior in the clinical and experimental amphetamine (model) psychosis. Am. J. Psychiatry 1973;130:1088-93. 
Eyles D, Feldon J, Meyer U. Schizophrenia: do all roads lead to dopamine or is this where they start? Evidence from two epidemiologically informed developmental rodent models. Transl. Psychiatry 2012;2:e81.

Feleder C, Tseng KY, Calhoon GG, O'Donnell P. Neonatal intrahippocampal immune challenge alters dopamine modulation of prefrontal cortical interneurons in adult rats. Biol. Psychiatry 2010;67:386-92.

Geyer MA, Krebs-Thomson K, Braff DL, Swerdlow NR. Pharmacological studies of prepulse inhibition models of sensorimotor gating deficits in schizophrenia: a decade in review. Psychopharmacology (Berl). 2001;156:117-54.

Geyer MA, Moghaddam B. Animal models relevant to schizophrenia disorders. In: Neuropsychopharmacology: the fifth generation of progress. 2002:689-701.

Goldshmit Y, Greenhalgh CJ, Turnley AM. Suppressor of cytokine signalling-2 and epidermal growth factor regulate neurite outgrowth of cortical neurons. Eur. J. Neurosci. 2004a;20:2260-6.

Goldshmit Y, Walters CE, Scott HJ, Greenhalgh CJ, Turnley AM. SOCS2 Induces Neurite Outgrowth by Regulation of Epidermal Growth Factor Receptor Activation. J. Biol. Chem. 2004b;279:16349-55.

Green MJ, Matheson SL, Shepherd A, Weickert CS, Carr VJ. Brain-derived neurotrophic factor levels in schizophrenia: a systematic review with meta-analysis. Mol. Psychiatry 2011;16:960-72.

Greenhalgh CJ, Metcalf D, Thaus AL, Corbin JE, Uren R, Morgan PO, et al. Biological Evidence That SOCS-2 Can Act Either as an Enhancer or Suppressor of Growth Hormone Signaling. J. Biol. Chem. 2002;277:40181-4.

Grillon C, Ameli R, Charney DS, Krystal J, Braff D. Startle gating deficits occur across prepulse intensities in schizophrenic patients. Biol. Psychiatry. 1992;32:939-43.

Howes OD, Kapur S. The dopamine hypothesis of schizophrenia: version III--the final common pathway. Schizophr. Bull. 2009;35:549-62. 
Jegalian AG, Wu H. Differential roles of SOCS family members in EpoR signal transduction. J Interf. Cytok. Res. 2002;22:853-60.

Karl T, Duffy L, Scimone A, Harvey RP, Schofield PR. Altered motor activity, exploration and anxiety in heterozygous neuregulin 1 mutant mice: implications for understanding schizophrenia. Genes Brain Behav. 2007;6:677-87.

Laan W, Grobbee DE, Selten JP, Heijnen CJ, Kahn RS, Burger H. Adjuvant aspirin therapy reduces symptoms of schizophrenia spectrum disorders: results from a randomized, doubleblind, placebo-controlled trial. J. Clin. Psychiatry 2010;71:520-7.

Laruelle M. The role of endogenous sensitization in the pathophysiology of schizophrenia: implications from recent brain imaging studies. Brain Res. Brain Res. Rev. 2000;31:371-84.

Leite JV, Guimaraes FS, Moreira FA. Aripiprazole, an atypical antipsychotic, prevents the motor hyperactivity induced by psychotomimetics and psychostimulants in mice. Eur. J. Pharmacol. 2008;578:222-7.

Lewis DA, Curley AA, Glausier JR, Volk DW. Cortical parvalbumin interneurons and cognitive dysfunction in schizophrenia. Trends Neurosci. 2012;35:57-67.

Machado FS, Johndrow JE, Esper L, Dias A, Bafica A, Serhan CN, et al. Anti-inflammatory actions of lipoxin A4 and aspirin-triggered lipoxin are SOCS-2 dependent. Nat. Med. 2006;12:330-4.

Maes M, Bocchio Chiavetto L, Bignotti S, Battisa Tura GJ, Pioli R, Boin F, et al. Increased serum interleukin-8 and interleukin-10 in schizophrenic patients resistant to treatment with neuroleptics and the stimulatory effects of clozapine on serum leukemia inhibitory factor receptor. Schizophr. Res. 2002;54:281-91.

Mansbach RS, Geyer MA, Braff DL. Dopaminergic stimulation disrupts sensorimotor gating in the rat. Psychopharmacology (Berl). 1988;94:507-14.

Meltzer HY, Stahl SM. The dopamine hypothesis of schizophrenia: a review. Schizophr. Bull. 1976;2:19-76.

Metcalf D, Greenhalgh CJ, Viney E, Willson TA, Starr R, Nicola NA, et al. Gigantism in mice lacking suppressor of cytokine signalling-2. Nature 2000;405:1069-73. 
Meyer U, Feldon J. Prenatal exposure to infection: a primary mechanism for abnormal dopaminergic development in schizophrenia. Psychopharmacology (Berl). 2009;206:587602.

Meyer U, Feldon J, Schedlowski M, Yee BK. Towards an immuno-precipitated neurodevelopmental animal model of schizophrenia. Neurosci. Biobehav. Rev. 2005;29:91347.

Meyer U, Nyffeler M, Engler A, Urwyler A, Schedlowski M, Knuesel I, et al. The time of prenatal immune challenge determines the specificity of inflammation-mediated brain and behavioral pathology. J. Neurosci. 2006;26:4752-62.

Miller BJ, Buckley P, Seabolt W, Mellor A, Kirkpatrick B. Meta-analysis of cytokine alterations in schizophrenia: clinical status and antipsychotic effects. Biol. Psychiatry 2011;70:663-71.

Mita T, Hanada S, Nishino N, Kuno T, Nakai H, Yamadori T, et al. Decreased serotonin S2 and increased dopamine D2 receptors in chronic schizophrenics. Biol. Psychiatry 1986;21:1407-14.

Morris HM, Hashimoto T, Lewis DA. Alterations in somatostatin mRNA expression in the dorsolateral prefrontal cortex of subjects with schizophrenia or schizoaffective disorder. Cereb. Cortex 2008;18:1575-87.

Nawa H, Takei N. Recent progress in animal modeling of immune inflammatory processes in schizophrenia: implication of specific cytokines. Neurosci. Res. 2006;56:2-13.

Owen F, Cross AJ, Crow TJ, Longden A, Poulter M, Riley GJ. Increased dopamine-receptor sensitivity in schizophrenia. Lancet 1978;2:223-6.

Ozawa KK, Hashimoto KK, Kishimoto TT, Shimizu EE, Ishikura HH, Iyo MM. Immune activation during pregnancy in mice leads to dopaminergic hyperfunction and cognitive impairment in the offspring: a neurodevelopmental animal model of schizophrenia. Biol. Psychiatry 2006;59:546-54.

Patterson PH. Immune involvement in schizophrenia and autism: etiology, pathology and animal models. Behav. Brain Res. 2009;204:313-21. 
Paxinos G, Watson, C. The Rat Brain in stereotaxic coordinates. 5th edition ed: Elsevier Academic Press; 2005.

Peng RY, Mansbach RS, Braff DL, Geyer MA. A D2 dopamine receptor agonist disrupts sensorimotor gating in rats. Implications for dopaminergic abnormalities in schizophrenia. Neuropsychopharmacology 1990;3:211-8.

Perry W, Geyer MA, Braff DL. Sensorimotor gating and thought disturbance measured in close temporal proximity in schizophrenic patients. Arch. Gen. Psychiatry 1999;56:277-81.

Piessevaux J, Lavens D, Peelman F, Tavernier J. The many faces of the SOCS box. Cytokine Growth Factor Rev. 2008;19:371-81.

Potvin S, Stip E, Sepehry AA, Gendron A, Bah R, Kouassi E. Inflammatory cytokine alterations in schizophrenia: a systematic quantitative review. Biol. Psychiatry 2008;63:8018.

Ransome MI, Turnley AM. Analysis of neuronal subpopulations in mice over-expressing suppressor of cytokine signaling-2. Neuroscience 2005;132:673-87.

Ransome MI, Turnley AM. Growth hormone signaling and hippocampal neurogenesis: insights from genetic models. Hippocampus 2008;18:1034-50.

Rawlings JS, Rosler KM, Harrison DA. The JAK/STAT signaling pathway. J. Cell. Sci. 2004;117:1281-3.

Rico-Bautista E, Flores-Morales A, Fernandez-Perez L. Suppressor of cytokine signaling (SOCS) 2, a protein with multiple functions. Cytokine Growth Factor Rev. 2006;17:431-9.

Snyder SH. Amphetamine psychosis: a "model" schizophrenia mediated by catecholamines. Am. J. Psychiatry 1973;130:61-7.

Swerdlow NR, Braff DL, Masten VL, Geyer MA. Schizophrenic-like sensorimotor gating abnormalities in rats following dopamine infusion into the nucleus accumbens. Psychopharmacology (Berl) 1990;101:414-20.

Uren RT, Turnley AM. Regulation of neurotrophin receptor (Trk) signaling: suppressor of cytokine signaling 2 (SOCS2) is a new player. Front. Mol. Neurosci. 2014;7:39. 
van den Buuse M. Modeling the positive symptoms of schizophrenia in genetically modified mice: pharmacology and methodology aspects. Schizophr. Bull. 2010;36:246-70.

van den Buuse M, Garner B, Gogos A, Kusljic S. Importance of animal models in schizophrenia research. Aust. N. Z. J. Psychiatry 2005;39:550-7.

van den Buuse M, Garner B, Koch M. Neurodevelopmental animal models of schizophrenia: effects on prepulse inhibition. Curr. Mol. Med. 2003;3:459-71.

Vollenweider FX, Barro M, Csomor PA, Feldon J. Clozapine enhances prepulse inhibition in healthy humans with low but not with high prepulse inhibition levels. Biol. Psychiatry 2006;60:597-603.

Wang L, Zhang Z, Zhang R, Hafner MS, Wong HK, Jiao Z, et al. Erythropoietin up-regulates SOCS2 in neuronal progenitor cells derived from SVZ of adult rat. NeuroReport 2004;15:1225-9.

Weickert CS, Hyde TM, Lipska BK, Herman MM, Weinberger DR, Kleinman JE. Reduced brain-derived neurotrophic factor in prefrontal cortex of patients with schizophrenia. Mol. Psychiatry 2003;8:592-610.

Zakzanis KK, Hansen KT. Dopamine D2 densities and the schizophrenic brain. Schizophr. Res 1998;32:201-6. 


\section{A. Slice 1. MPFC B. Slice 2. NAc}
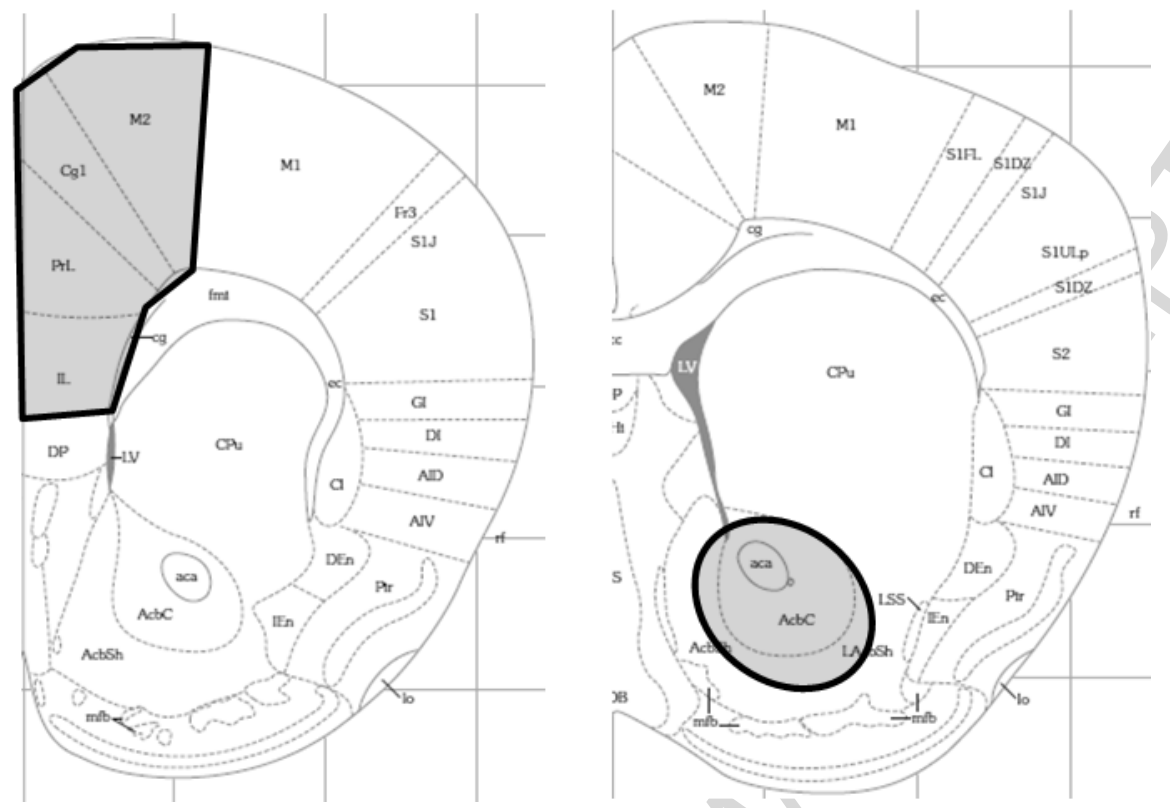

Figure 1 


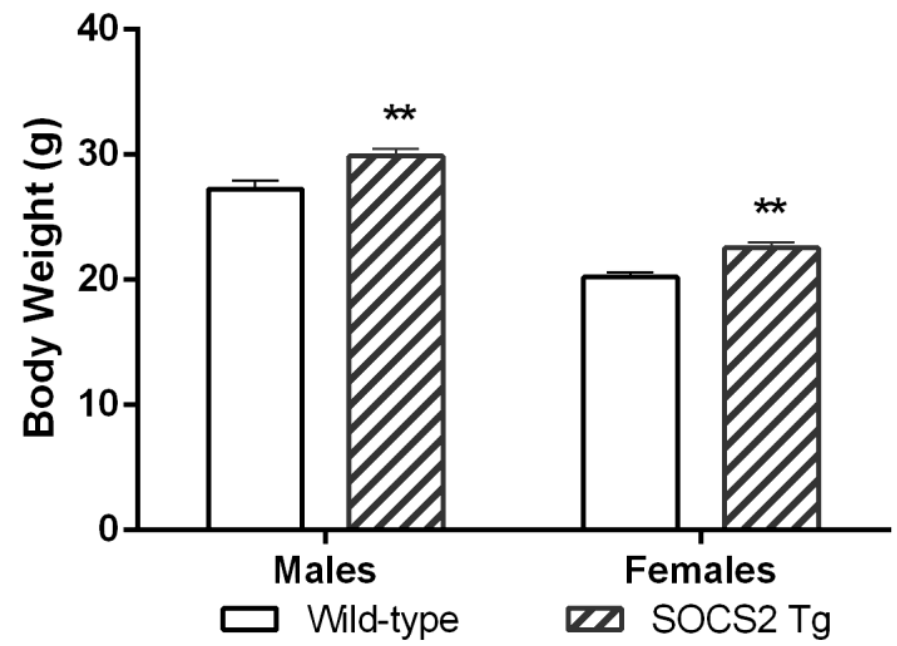

Figure 2 

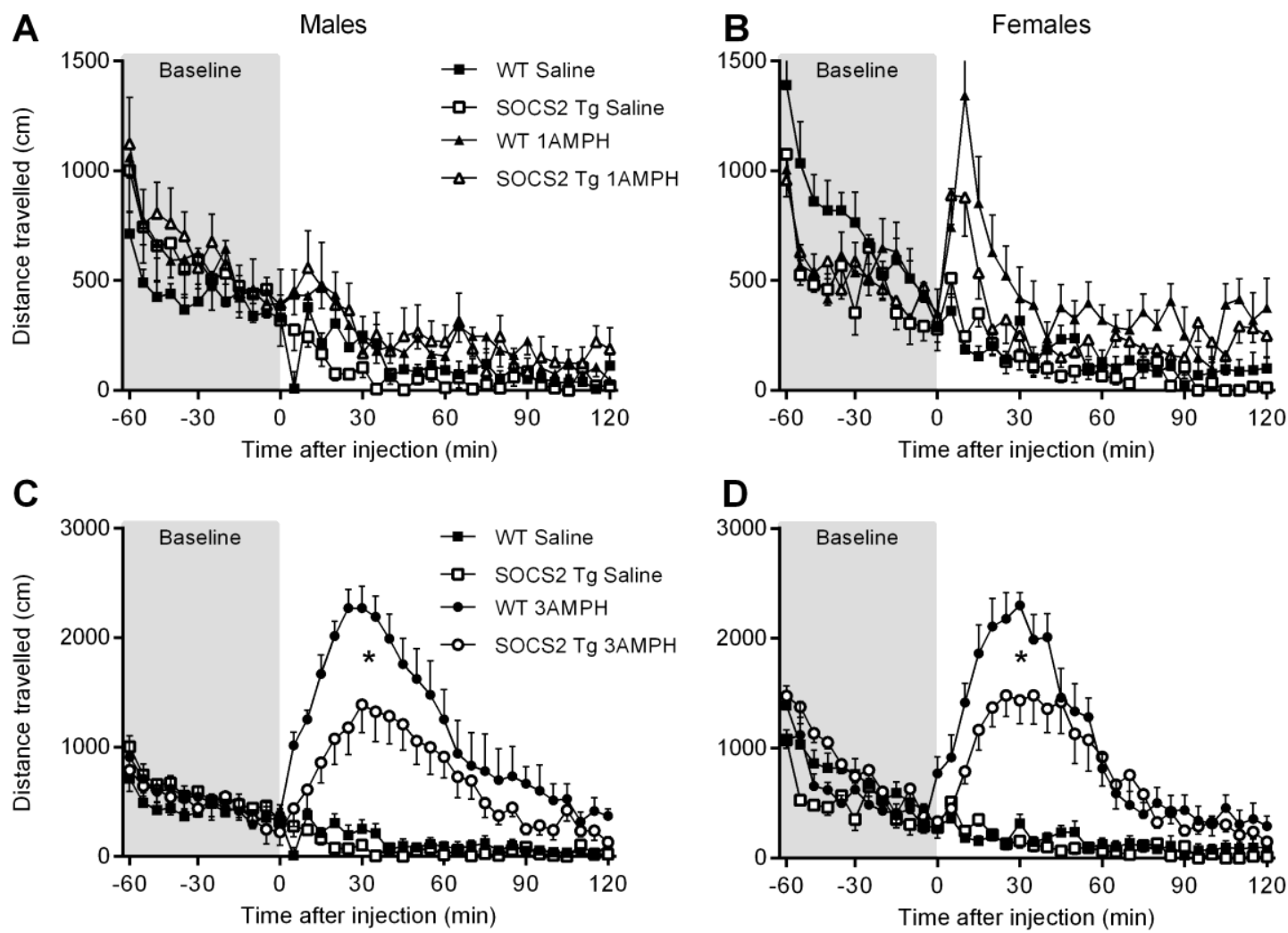

Figure 3 
A

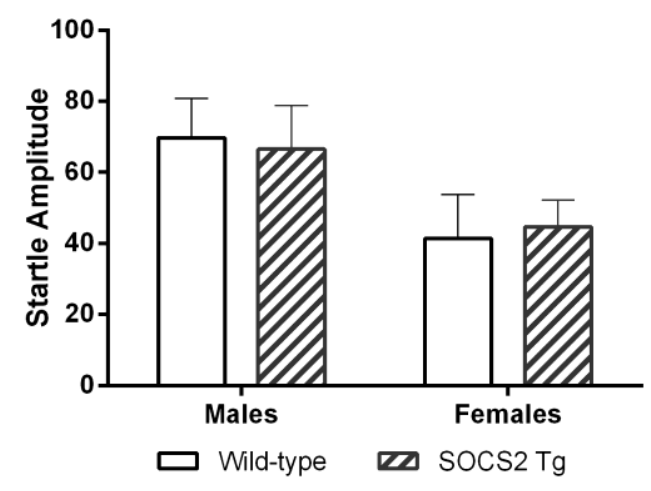

C

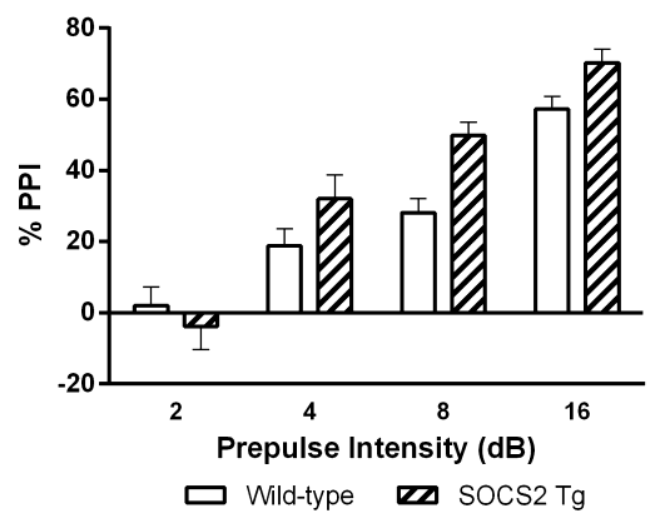

B

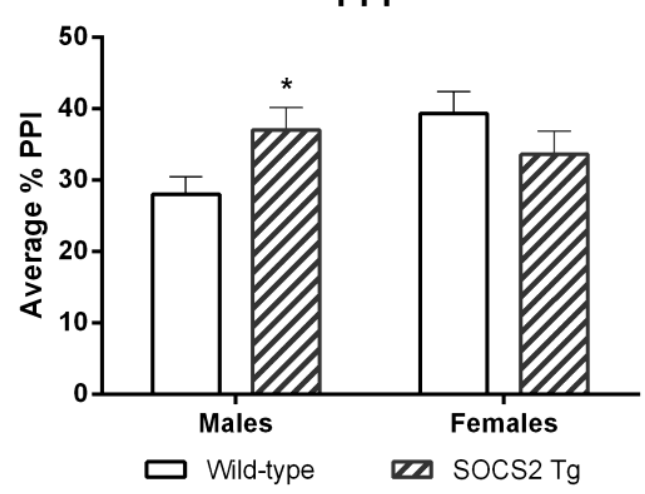

D

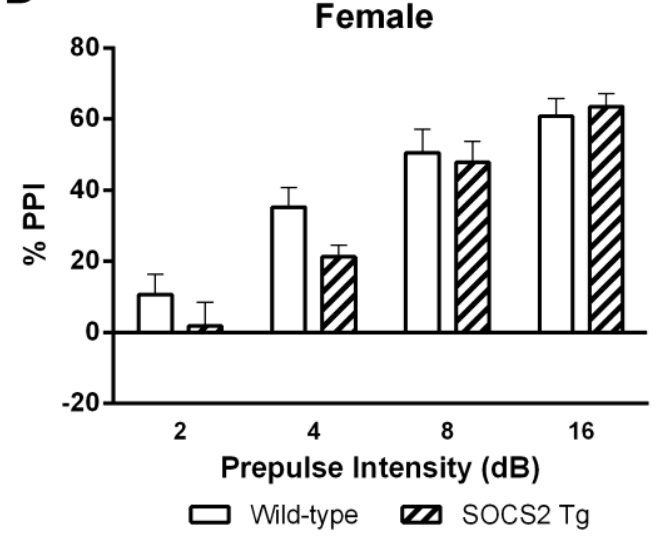

Figure 4 

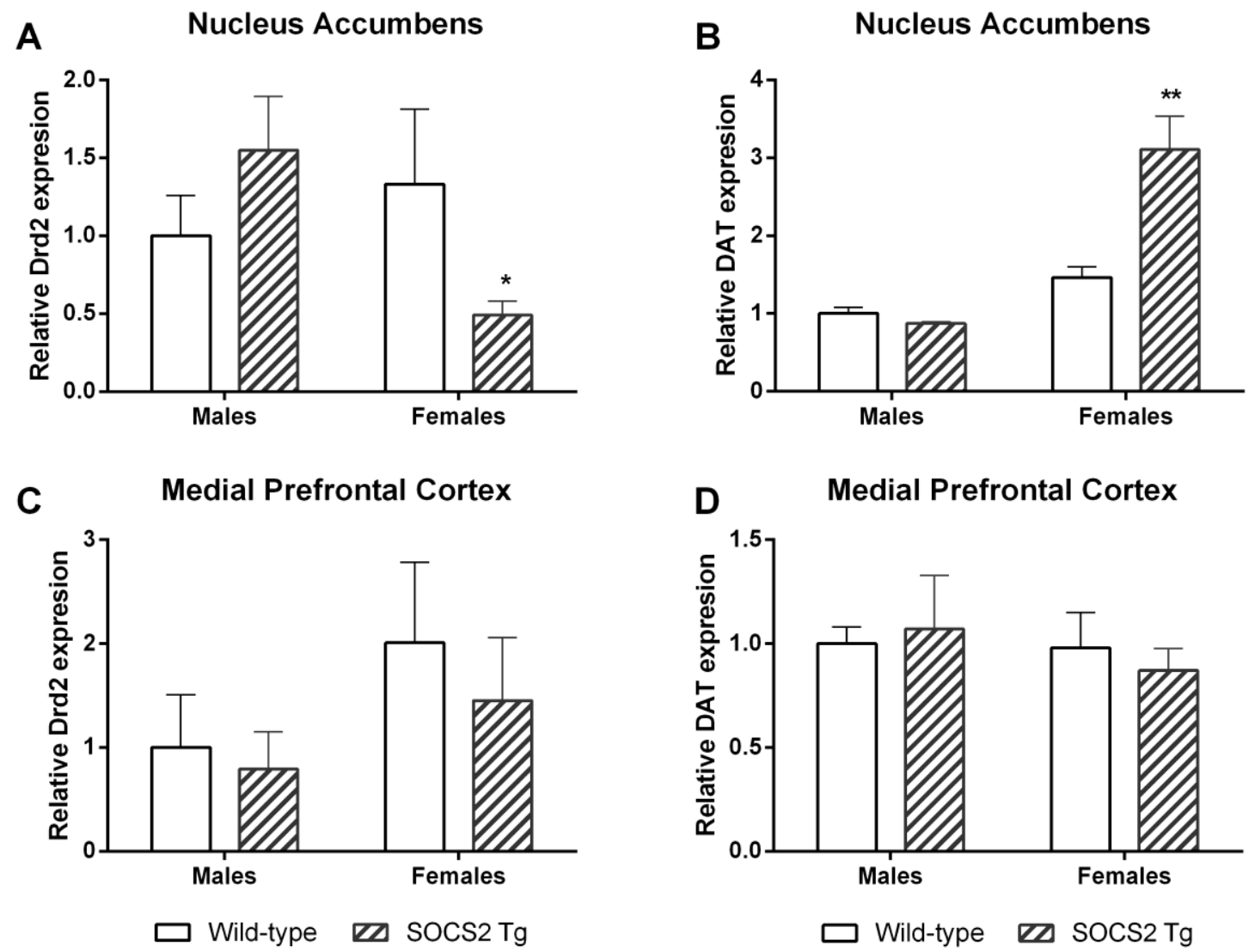

Figure 5 
$\underline{\text { Highlights }}$

- Suppressor of cytokine signalling 2 (SOCS2) regulates cytokine signalling

- SOCS2 trangenic mice showed reduced amphetamine-induced locomotor hyperactivity

- Male, but not female SOCS2 transgenic mice showed increased prepulse inhibition

- Alterered dopamine transporter and D2 receptor expression in female transgenics

- SOCS2 may be new target for development of schizophrenia therapeutics 


\section{University Library}

\section{- M M I N E R VA A gateway to Melbourne's research publications}

Minerva Access is the Institutional Repository of The University of Melbourne

Author/s:

Ratnayake, U;Basrai, HS;Turnley, AM;van den Buuse, M

Title:

Dopaminergic activity and behaviour in SOCS2 transgenic mice: Revealing a potential drug target for schizophrenia

Date:

2015-01-02

\section{Citation:}

Ratnayake, U., Basrai, H. S., Turnley, A. M. \& van den Buuse, M. (2015). Dopaminergic activity and behaviour in SOCS2 transgenic mice: Revealing a potential drug target for schizophrenia. PROGRESS IN NEURO-PSYCHOPHARMACOLOGY \& BIOLOGICAL PSYCHIATRY, 56, pp.247-253. https://doi.org/10.1016/j.pnpbp.2014.09.009.

Persistent Link:

http://hdl.handle.net/11343/58449 